\title{
Acute Generalized Peritonitis in Intensive Care Unit at University Hospital of Brazzaville, Republic of Congo: Etiological, Therapeutic Aspects and Issues
}

\author{
Christ Mayick Mpoy Emy Monkessa ${ }^{1,2 *}$, Peggy Dahlia Gallou Leyono-Mawandza ${ }^{1,3}$, \\ Marie Elombila1,3, Gilles Niengo Outsouta ${ }^{1,2}$, Marina Aurole Bokoba-Nde Ngala ${ }^{1,4}$, \\ Giresse Bienvenu Tsouassa Wa Ngono5, Gilbert Fabrice Otiobanda1,3
}

\footnotetext{
${ }^{1}$ Polyvalent Intensive Care Unit, University Hospital of Brazzaville, Brazzaville, Republic of Congo

${ }^{2}$ Anesthesia and Resuscitation Resident, Cheikh Anta Diop University, Dakar, Senegal

${ }^{3}$ Faculty of Heath Sciences, Marien N'Gouabi University, Brazzaville, Republic of Congo

${ }^{4}$ Anesthesia and Resuscitation Resident, Cadi Ayyad University, Marrakech, Morocco

${ }^{5}$ Department of Visceral Surgery, University Hospital of Brazzaville, Brazzaville, Republic of Congo

Email: ${ }^{*}$ christerad@gmail.com
}

How to cite this paper: Mpoy Emy Monkessa, C.M., Leyono-Mawandza, P.D.G., Elombila, M., Niengo Outsouta, G., Bokoba-Nde Ngala, M.A., Tsouassa Wa Ngono, G.B. and Otiobanda, G.F. (2020) Acute Generalized Peritonitis in Intensive Care Unit at University Hospital of Brazzaville, Republic of Congo: Etiological, Therapeutic Aspects and Issues. Open Journal of Emergency Medicine, 8, 86-94.

https://doi.org/10.4236/ojem.2020.84010

Received: October 13, 2020

Accepted: November 16, 2020

Published: November 19, 2020

Copyright $\odot 2020$ by author(s) and Scientific Research Publishing Inc. This work is licensed under the Creative Commons Attribution International License (CC BY 4.0).

http://creativecommons.org/licenses/by/4.0/

\begin{abstract}
Aim: To determine etiological, therapeutic aspects and issues of AGP in intensive care unit (ICU) at University Hospital of Brazzaville (UHB). Materials and Methods: It was a retrospective and descriptive study carried out from January to December 2016 in ICU at UHB. We collected completed medical records of patients admitted and operated for AGP regardless of age or sex. The parameters studied were age, sex, admission's reasons, etiologies, management, post-operative complications, length of hospital and mortality. Data were treated in Excel 2010 and Epi info 2007. Results: Thirty-one complete medical records were identified (mean age: $40.6 \pm 22.0$ years). The sex ratio was 2.4. Shock was the most common reason for admission with $67.7 \%$ of the cases. The etiologies of AGP were dominated by gastroduodenal perforating ulcer (41.9\%) followed by complicated appendicitis (19.4\%). The management of all patients was medico-surgical. The bi antibiotic ceftriaxone-metronidazole was administered in 29 patients (93.6\%). 18 patients (59.1\%) received vasopressor therapy. The complications had occurred among 9 patients i.e. $29 \%$ of the cases; parietal suppurations represented $44.5 \%$ of the complications. The average length of hospitalization was $5.2 \pm$ 4.6 days. The overall mortality was $41.9 \%$. Conclusion: In our study, the most frequent etiologies were gastroduodenal perforating ulcer and complicated appendicitis. They affected young patients. The complications were
\end{abstract}


dominated by parietal suppurations. The mortality rate was high.

\section{Keywords}

Acute Generalized Peritonitis, Brazzaville, Etiologies, Intensive Care Unit, Issues

\section{Introduction}

Acute generalized peritonitis (AGP) is defined as acute and diffuse inflammation of the peritoneal serous membrane. They constitute one of the most frequent abdominal surgical emergencies and one of the leading causes of septic shock, involving, in the short term, the vital prognosis of the patient [1] [2]. They are classified into three types: primary or primitive, secondary and tertiary. Their etiologies are multiple and varied but have in common the therapeutic urgency. The positive diagnosis of AGP is essentially clinical and most often easy; management is multidisciplinary [3] [4].

Despite many advances and progress in the management of this pathology, morbidity and mortality remain high, particularly in developing countries due to delayed diagnosis and therapeutic [5] [6] [7]. With regard to AGP requiring intensive care, the data are relatively absent, thus justifying this study.

The aim of our study was to determine etiological, therapeutic and evolutionary aspects of AGP in intensive care unit (ICU) at University Hospital of Brazzaville (CHU-B).

\section{Materials and Methods}

This was a retrospective and descriptive study carried out in polyvalent ICU at CHU-B from January 1 to December 31, 2016. Our general study population consisted of paper records of patients operated on for PAG and admitted in polyvalent ICU. We included all complete records of patients operated for AGP regardless of age or sex. Patients with missing data or unusable records were excluded from our study. The data was collected from the operating room register, the ICU admissions register and medical records written by the medical team and archived by supervisors. A survey sheet was used for the collection of intra operative and postoperative data. The following parameters were studied: age, sex, reasons for admission, etiologies, management, postoperative complications, length hospitalization and mortality.

The statistical analysis was performed using Excel 2010 and Epi-info version 7 software for Windows. The quantitative variables were expressed as an average \pm standard deviation and the qualitative variables were expressed as numbers and percentages.

The CHU-B is a public health establishment with 876 beds divided into several departments, including polyvalent intensive care. This department had 11 
beds, 7 of which were functional during the study period. It takes care of patients, including those presenting a surgical pathology, who require specific means of management such as ventilator assistance, administration of vasopressor amines, continuous monitoring, etc. During the study period, the department of ICU had a medical team of four anesthesiologists-resuscitators (MAR) and four general practitioners (MG) and a paramedical team comprising, for each group, two nurses, a technical health worker and a hospital service worker. Hospital care was provided by the MAR/MG couple 24 hours a day and seven days a week. The admission of patients in ICU was conditioned by the opinion of the doctors on call.

\section{Results}

During the study period, thirty-one records of patients operated for AGP were collected and analyzed. The average age of our patients was $40.6 \pm 22.0$ years with extremes ranging from 7 to 81 years old. The 21 to 40 age group was the most represented with 11 patients, representing $35.5 \%$ of cases (Figure 1). We recorded 22 men (71.0\%) and nine women (29.0\%), for a sex ratio of 2.4 . The reasons for admission concerned the state of shock 21 cases (67.7\%), surveillance and post-operative care eight cases (25.8\%), delay of walking a case and respiratory distress a case. Peritonitis by gastroduodenal perforation was found in 13 patients (41.9\%) and appendicular peritonitis in six patients (19.3\%). The main etiologies of AGP are shown in Table 1.

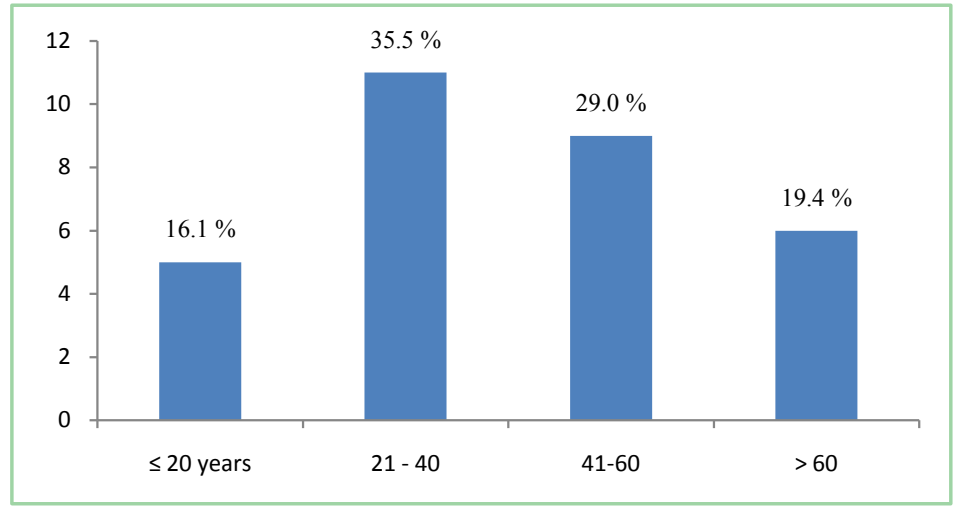

Figure 1. Distribution of patients operated for AGP by age group.

Table 1. Distribution of patients operated for AGP by etiologies.

\begin{tabular}{cc}
\hline & Effective (percentage) \\
\hline Gastroduodenal perforations & $13(41.9 \%)$ \\
Appendicular peritonitis & $6(19.3 \%)$ \\
Postoperative peritonitis & $4(12.9 \%)$ \\
Primary peritonitis & $3(9.7 \%)$ \\
Ileal perforation & $2(6.5 \%)$ \\
Intestinal necrosis & $2(6.5 \%)$ \\
Intestinal necrosis & $1(3.2 \%)$ \\
Total & $31(100.0 \%)$ \\
\hline
\end{tabular}


The management of the patients was medico-surgical. The medical treatment consisted of hemodynamic management by vascular filling and possibly the administration of catecholamines combined with preoperative antibiotherapy as soon as the diagnosis of AGP was made and was continued per and postoperatively. The antibiotic therapy performed was either double or triple depending on the case, targeting aerobic and anaerobic germs. Parenteral bi-antibiotic therapy with ceftriaxone-metronidazole was administered in 29 patients (93.6\%) either alone or in combination with gentamycin or ciprofloxacin (Table 2). Blood transfusion was performed in 6 patients, $19.4 \%$ of cases. The use of catecholamines, in particular norepinephrine alone or in addition to dobutamine or adrenaline, was necessary in 18 patients, i.e. 59.1\% of cases. All patients had vascular filling guided by clinical and ultrasound data. Postoperative complications were found in 9 patients, i.e. $29.0 \%$ of cases. They were dominated by parietal suppurations in 4 cases (44.5\%). Three patients (33.3\%) had postoperative cardiovascular complications, namely a case of ischemic stroke, a case of ischemic heart disease and a case of peripheral arterial occlusive disease. The postoperative complications found are shown in Figure 2. The average length of hospitalization was $5.2 \pm 4.6$ days.

In our study 13 of 31 patients died, with a mortality rate of $41.9 \%$. The cause of death in all patients was septic shock complicated by multiple organ failure.

\section{Discussion}

For a better analysis and interpretation of our results, a number of limitations must be taken into account. Its retrospective nature did not allow us to have a much larger sample due to the existence of missing data and poses the problem of computerizing medical records. The absence of preoperative data such as the duration of the symptoms, the existence or not of signs of severity on admission to the emergency room, the time taken to take charge of patients in the emergency rooms and in the operating room and the action to be taken preoperative were also limitations in our study. The small size of our study and the monocentric aspect do not allow us to extend these results to the national level. However, it provides a basis on which to build for future studies.

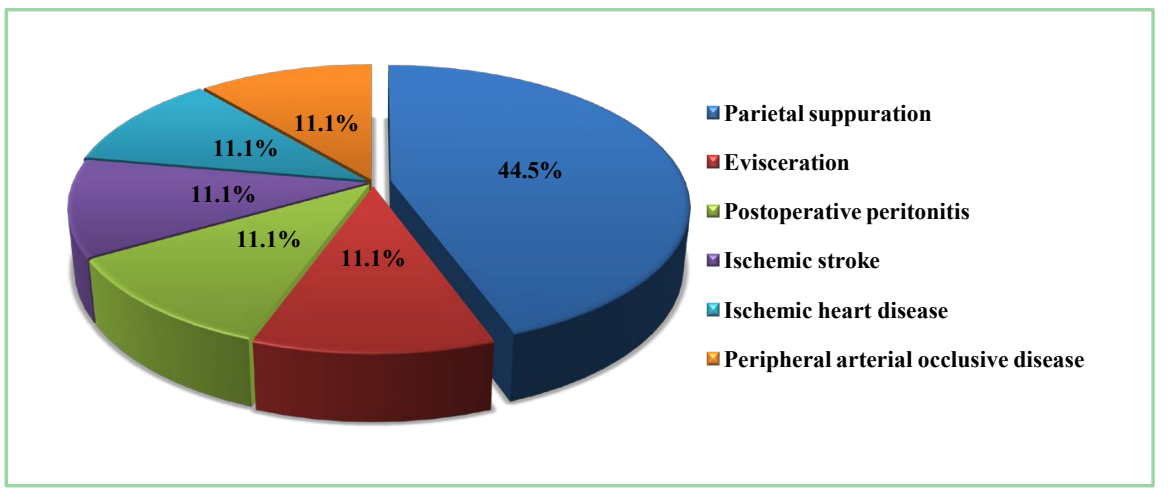

Figure 2. Distribution of patients operated for AGP by postoperative complications. 
Table 2. Distribution of patients operated for AGP by antibiotic therapy.

\begin{tabular}{cc}
\hline & Effective (percentage) \\
\hline Ceftriaxone-metronidazole & $11(35.5 \%)$ \\
Ceftriaxone-ciprofloxacin & $1(3.2 \%)$ \\
Ceftriaxone-gentamycin & $1(3.2 \%)$ \\
Ceftriaxone-metronidazole-gentamycin & $16(51.6 \%)$ \\
Ceftriaxone-metronidazole-ciprofloxacin & $2(6.5 \%)$ \\
Total & $31(100.0 \%)$ \\
\hline
\end{tabular}

In our study, we collected 31 cases of AGP on 769 ICU admissions, a relative frequency of $4.03 \%$. The average age of our patients was $40.6 \pm 22.0$ years with extremes ranging from 7 to 81 years old. This result corroborates those of Gaye and others as well as Azgaou and others who respectively reported an average age of 41 and 39.2 years in their different series [8] [9]. However, other authors have reported a lower average age than ours in their respective studies [5] [10] [11].

The study population was predominantly male. This predominance has also been reported by several authors [8] [12] [13] [14]. The most common reason for admission in our study was shock in $67.7 \%$ of cases. This result is comparable to that of Mehinto and others, who reported $69.2 \%$ shock in their study of tinnitus hail perforations in visceral surgery in Cotonou [15]. This is explained exclusively by the delay of consultation and management. Our study revealed that peritonitis by gastroduodenal perforations were the most common etiologies followed by appendicular peritonitis. Some authors have noted the same trend [5] [10] [16]. Kambire and others for their part reported that the main etiologies were gastroduodenal perforations followed by non-traumatic ileal perforation and appendicular peritonitis [17]. The predominance of gastroduodenal lesions could be explained by the misuse of self-medication based on nonsteroidal anti-inflammatory drugs in the presence of abdominal pain. As for appendicular peritonitis, their frequency was justified by the delay in diagnosis and management of appendicitis. This delay was most often due to the initial use of traditional treatment, patients' financial difficulties in fulfilling medical prescriptions, but also to organizational problems such as the patient's circuit, the availability of the operating room, and the time taken to acquire additional examinations. However, other authors have identified ileal perforation of typhoid origin as the main etiology of AGP in their respective studies [13] [18] [19] [20]. This difference could be explained by the difference in the study frameworks. Indeed, their studies were carried out in rural areas, areas where hygiene conditions remain precarious.

Treatment of AGP is medical-surgical and must be early. It uses hemodynamic and hydro-electrolytic resuscitation, good antibiotic therapy and control of the source of infection requiring surgery in most cases [21] [22]. In our study, all patients underwent preoperative resuscitation. In fact, it is recommended that resuscitation of patients with arterial hypotension resistant to a vascular filling of $30 \mathrm{~mL} / \mathrm{kg}$ crystalloid solutes be initiated immediately to minimize progression to 
severe sepsis or septic shock [23]. Antibiotic therapy was systematic in all patients and probabilistic associating at least ceftriaxone and metronidazole in 93.6\% of cases. According to the literature, the antibiotherapy of AGP must be intravenous and started within one hour after the diagnosis of this pathology because any delay of 10 minutes increases mortality by $1 \%$. It must target gram-negative bacilli and anaerobic germs [11] [23]. The use of a vasoactive drug, particularly norepinephrine, affected $59.1 \%$ of our patients. Indeed, it is the vasopressor treatment of choice which must be started, even on peripheral path of good caliber, when the volume expansion did not allow to obtain a satisfactory average arterial pressure (PAM) allowing the infusion of organs [23].

In our study, postoperative complications were observed in $29 \%$ of cases. This result is comparable to that of Dieng and others, who reported a rate of $30.7 \%$ in their study on factors of AGP in Senegal [5]. Relatively higher rates have been reported by other authors [10] [13] [20] [24]. These complications were dominated by parietal suppurations accounting for $44.5 \%$ of overall morbidity. These results are supported by several studies [5] [10] [13] [24]. This could be explained by the gravity of AGP requiring urgent care, the rules of strict care, the difficulty of respecting the rules of strict asepsis in the operating room, the follow-up of operative wounds. The average length of hospitalization was $5.2 \pm 4.6$ days in our study. Kassegne and others as well as Kante and others found 15 and 12.1 days, respectively, as the average length of hospitalization for patients [13] [24]. The short duration of hospitalization found in our study is explained by the fact that the ICU is reserved only for patients with vital distress.

Despite advances and progress in the management of peritonitis, mortality remains high, especially in developing countries [2]. In our study, the mortality rate was $41.9 \%$. This result is similar to that of Dieng and others who reported a mortality rate of $40.0 \%$ of patients who had resuscitated [5]. Rasamoelina and others reported a mortality rate of $37.5 \%$ in their study of mortality factors by digestive emergencies in the ICU in Madagascar [25]. This could be explained by the delay between the onset of symptoms and consultation, the delay in evacuation and referral of patients, the severity of the symptomatology at admission, the insufficiency of initial resuscitation, the low economic level of the patients who don't allow them to honor expensive medical prescriptions. Other authors have reported a much lower mortality rate of between $4.9 \%$ and $19.0 \%$ [8] [11] [20] [24].

\section{Conclusion}

The AGP is a real medical and surgical emergency. It affected young patients. Its etiologies are diverse and varied; peritonitis by gastroduodenal perforation and appendicular peritonitis being the most frequent etiologies in our study. The management of AGP is multidisciplinary and requires good coordination between surgeons and anesthetists-intensive care despite facing financial difficulties especially. The complications were dominated by parietal suppuration. Mortality related to this pathology was high. 


\section{Ethical Clearance: Not Necessary}

Clearance from the Ethics Committee was not required for the development of this work.

\section{Authors' Contributions}

All authors contributed to review concept, design and acquisition, analysis and interpretation of the literature. Finally, all authors read and approved the submitted manuscript.

\section{Conflicts of Interest}

The authors declare no conflicts of interest regarding the publication of this paper.

\section{References}

[1] Skipworth, R.J.E. and Fearon, K.C.H. (2008) Acute Abdomen: Peritonitis. Surgery (Oxford), 26, 98-101. https://doi.org/10.1016/j.mpsur.2008.01.004

[2] Montravers, P., Allyn, J. and Olinca, A. (2011) Prise en charge des péritonites. Journal des Anti-infectieux, 13, 25-33. https://doi.org/10.1016/j.antinf.2011.01.003

[3] Jovanovic, D., Loncar, Z., Doklestic, K. and Karamarkovic, A. (2015) Intra-Abdominal Infection and Acute Abdomen-Epidemiology, Diagnosis and General Principles of Surgical Management. Sanamed, 10, 69-78. https://doi.org/10.5937/sanamed1501069J

[4] Mulari, K. and Leppäniemi, A. (2004) Severe Secondary Peritonitis Following Gastrointestinal Tract Perforation. Scandinavian Journal of Surgery, 93, 204-208. https://doi.org/10.1177/145749690409300306

[5] Dieng, M., Ndiaye, A., Konaté, I., Ka, O., Cissé, M., Dia, A., et al. (2007) Etude des facteurs de morbidité et de mortalité des péritonites aiguës généralisées: à propos d'une série de 221 cas opérés. Journal Africain de chirurgie Digestive, 7, 679-685.

[6] Montravers, P., Dupont, H., Leone, M., et al. (2015) Prise en charge des infections intra-abdominales. Anesthésie \& Réanimation, 1, 75-99. https://doi.org/10.1016/j.anrea.2014.12.006

[7] Hadley, G.P. (2014) Intra-Abdominal Sepsis-Epidemiology, Aetiology and Management. Seminars in Pediatric Surgery, 23, 357-362. https://doi.org/10.1053/j.sempedsurg.2014.06.008

[8] Gaye, I., Leye, P.A., Traoré, M.M., Ndiaye, P.I., Ba, E.H.B., Bah, M.D., et al. (2016) Prise en charge péri opératoire des urgences chirurgicales abdominales chez l'adulte au CHU Aristide Le Dantec. The Pan African Medical Journal, 24, 190. http://www.panafrican-med-journal.com/content/article/24/190/full/ https://doi.org/10.11604/pamj.2016.24.190.9929

[9] Azgaou, I., Benomar, R., Benelkhaiat and Finech, B. (2011) Profil épidémiologique, clinique et thérapeutique des péritonites aiguës: étude rétrospective sur 2 ans au CHU Mohamed VI de Marrakech.

[10] Ngo Nonga, B., Mouafo Tambo, F.F., Ngowe Ngowe, M., Takongmo, S. and Sosso, M.A. (2010) Etiologies des péritonites aiguës généralisées au CHU de Yaoundé. Revue Africaine de Chirurgie et Spécialités, 4, 30-32. https://doi.org/10.4314/racs.v4i7.66378 
[11] Rakotomavo, F.A., Riel, A.M., Rakotoarison, R.C.N., Randrianambinina, H., Randrianambinina, T. and Randriamiarana, M. (2012) Péritonite aigüe: Aspects épidémio-clinique et étiologique dans un service des urgences chirurgicales malgache. A propos de 60 cas. Journal Africain d'Hépato-Gastroentérologie, 6, 33-37. https://doi.org/10.1007/s12157-011-0355-2

[12] Coulibaly, B., Togola, B., Traoré, D., Coulibaly, M., Diallo, S., Sanogo, S., et al. (2013) Péritonites postopératoires dans le service de chirurgie B du CHU du Point G. Mali Medical, 28, 10-12.

[13] Kassegne, I., Kanassoua, K.K., Sewa, E.V., Tchangai, B., Sambiani, D.M., Ayite, A.E., et al. (2016) Prise en charge des péritonites aiguës généralisées au Centre Hospitalier Universitaire de Kara. Revue Africaine d'Anesthésiologie et de Médecine d'Urgence, 18.

[14] Harouna, Y.D., Abdou, I., Saidou, B. and Bazira, L. (2001) Les péritonites en milieu tropical: Particularités étiologiques et facteurs pronostiques actuels-A propos de 160 cas. Médecine d'Afrique Noire, 48, 103-106.

[15] Mehinto, D.K., Gandaho, I., Adoukonou, O., Bagnan, O.K. and Padonou, N. (2010) Aspects épidémiologiques, diagnostiques et thérapeutiques des perforations du grêle d'origine typhique en chirurgie viscérale du Centre National Hospitalier et Universitaire-Hubert Koutoucou Maga de Cotonou. Médecine d'Afrique Noire, 57, 535-540.

[16] Doklestić, S.K., Bajec, D.D., Djukić, R.V., Bumbaširević, V., Detanac, A.D., Detanac, S.D., et al. (2014) Secondary Peritonitis-Evaluation of 204 Cases and Literature Review. Journal of Medicine and Life, 7, 132-138.

[17] Kambiré, J.L., Zaré, C., Sanou, B.G. and Kambou, T. (2017) Étiologies et pronostic des péritonites secondaires au centre hospitalier universitaire de Bobo-Dioulasso (Burkina Faso). Journal Africain D'Hepato-Gastroenterologie, 11, 149-151. https://doi.org/10.1007/s12157-017-0719-3

[18] Sanogo, Z.Z., Camara, M., Doubia, M.M., et al. (2012) Perforations digestives au CHU du Point-G. Mali Medical, 27, 19-22.

[19] Harissou, A., Ibrahim, A.M., Oumarou, H., Mansour, A., Amadou, M., Ousseni, E.A., et al. (2015) Retard diagnostique et implication pronostique en milieu africain. Cas des urgences en chirurgie digestive à l'Hôpital national de Zinder, Niger. European Scientific Journal, 11, 251-262.

[20] Ouangre, E., Zida, M., Bonkoungou, P.G., Sanou, A. and Traoré, S.S. (2013) Les péritonites aigües généralisées en milieu rural au Burkina Faso: à propos de 221 cas. Revue Africaine et Malgache de Recherche Scientifique/Sciences de la Santé, 1, 75-79.

[21] Lopez, N., Kobayashi, L. and Coimbra, R. (2011) A Comprehensive Review of Abdominal Infections. World Journal of Emergency Surgery, 6, 7. https://doi.org/10.1186/1749-7922-6-7

[22] Sartelli, M., Viale, P., Koike, K., et al. (2011) WSES Concensus Conference: Guideline for First-Line Management of Intra-Abdominal Infections. World Journal of Emergency Surgery, 6, 2. https://doi.org/10.1186/1749-7922-6-2

[23] Michel, F., Leone, M. and Martin, C. (2015) Prise en charge du sepsis grave et du choc septique: Survivre au sepsis. Le Praticien en Anesthésie Réanimation, 19, 147-152. https://doi.org/10.1016/j.pratan.2015.04.003

[24] Kanté, L., Diakité, I., Togo, A., Dembélé, B.T., Traoré, A., Maiga, A., et al. (2013) Péritonites aiguës généralisées à l'hôpital SOMINE DOLO DE MOPTI: Aspects épidémiologique et thérapeutique. Mali Medical, 28, 20-23.

[25] Rasamoelina, N., Rajaobelison, T., Ralahy, M.F., Riel, A.M., Rabarijaona, M., Solofoma- 
lala, G.D., et al. (2010) Facteurs de mortalité par les urgences digestives dans le service de réanimation du CHU de Fianarantsoa Madagascar. Revue D’anesthésie-Réanimation et de Médecine D’urgence, 2, 10-11. https://doi.org/10.1007/s12157-017-0706-8 